\title{
Above and beyond the call. Long-term real earnings effects of British male military conscription in the post-war years
}

\author{
Julien Grenet* \\ Centre for Economic Performance \\ London School of Economics \\ Robert A. Hart \\ Division of Economics \\ University of Stirling and IZA \\ J. Elizabeth Roberts \\ Division of Economics \\ University of Stirling
}

August, 2010

\begin{abstract}
We add to the literature on the long-term economic effects of male military service. We concentrate on post-war British conscription into the armed services from 1949 to 1960 . It was called National Service and applied to males aged 18 to 26. Based on a regression discontinuity design we estimate the effect of military service on the earnings of those required to serve through conscription. We argue that, in general, we should not expect to find large long-term real earnings among conscripts compared to later birth cohorts of males who were not eligible for call-up. Our empirical evidence firmly rejects the view that conscription entails relative long-term real earnings differences.
\end{abstract}

JEL Classification: J24, J31, N44

Key Words: National Service; WWII conscription; long-term real earnings; regression discontinuity design

Acknowledgements: Research was funded by ESRC Grant RES-000-22-2899. We acknowledge the Office for National Statistics (ONS) for granting access to the NESPD and the ONS and Economic and Social Data Service (ESDS) for access to the General Household Survey and the Family Expenditure Survey. We are grateful to David French for invaluable guidance on historical detail and interpretation. A referee raised detailed and very helpful points. We thank Sascha Becker, Paul Devereux and George Peden who offered useful advice and comments. All remaining errors reside with us.

* Corresponding author 


\section{Introduction}

How does male military service affect longer term civilian labour market prospects? This question has been investigated along three distinct lines of enquiry in relatively recent times. These encompass research into the economic effects of (a) the Vietnam draft (Angrist, 1990; Angrist and Krueger, 1994), (b) voluntary military service in the U.S. (Angrist, 1998), and (c) peacetime compulsory military service in Europe (Imbens and van der Klaauw, 1995; Buonanno, 2007; Bauer, Bender, Paloyo and Schmid, 2009). A major theme that runs through all of this work concerns the effect of military service on future real earnings. Most of these studies find varying degrees of deleterious effects of service on later earnings outcomes. Bauer et al. (2009), however, find that there are no negative earnings effects linked to the German military draft in the 1950s. Moreover, several earlier U.S. studies show that military service and training can lead to positive earnings outcomes among those who served in the military compared to those who never served (see Mangum and Ball, 1989, for a review).

This paper belongs to the third area of research. Based on a regression discontinuity design (RDD), it compares the long-term real earnings outcomes of men who were conscripted into the British armed services from 1949 to the end of 1960 with later male cohorts who were not eligible for compulsory service. This episode of conscription was universally referred to as National Service and involved men aged 18 to 26. We find no evidence of differences in earnings outcomes between eligible and not eligible groups. In general, we argue that we should not necessarily expect major longterm real earnings disadvantages for those experiencing a period of conscription 
compared to subsequent birth cohorts who were exempt. Essentially, we say more on the central hypothesis of Angrist (1990) which holds that those who served in the military "earn less because their military experience is only a partial substitute for the civilian labor market experience lost while in the armed forces". We outline the main socio-economic costs and benefits of conscription and conclude that it is difficult to make a priori judgements concerning longer term net labour market outcomes.

We offer three major areas of added value compared to earlier related work. First, our data on postings into the armed services are necessarily obtained from a different source from our pay data. Accordingly, we employ Two Sample Two Stage Least Squares (TS2SLS) to obtain instrumental variable estimates of the effects of conscription on wage earnings. We estimate the local average treatment effect, that is the effect of military service on the earnings of those forced to serve through conscription. Second, our RDD incorporates a comprehensive allocation of military postings by birth cohorts. Of particular interest, we find that significant proportions of eligible conscripts were not called-up at the earliest possible date but, rather, had their postings deferred to later years. We show that accounting for deferments within the conscription data has radical implications for estimated outcomes compared to earlier related work in which deferments were not properly accommodated (Buonnano, 2007; Hart, 2009). Third, we assess implications for estimated earnings effects when taking into consideration the fact that many males towards the end of the period of National Service avoided call-up by either taking up or prolonging existing industrial or academic training. 


\section{Post-war British Conscription, 1949 - 1960}

Under the National Service Act 1948, 'peacetime' conscription to the armed services was introduced in Great Britain in January 1949. Up to October 1950, conscription lasted for a period of 18 months and then, in response to the Korean War, it was extended to 2 years. All males aged between 18 and 26 were liable to register for this so-called National Service. ${ }^{1}$ Conscription was ended in December, 1960 . Table 1 shows the proportions of men born in the years 1930 to 1939 - i.e. the cohorts eligible for conscription - who were subsequently posted into the armed services during the period of National Service. ${ }^{2}$ The postings data are taken from Wallis (1977) who has meticulously assembled the full information using 40 official government reports, mostly consisting of Annual Reports of the Ministry of Labour and National Service from 1946 to 1958 and of the Ministry of Labour 1959 and 1960. From column (1), we see that two-thirds of men born in 1930 to 1932 were eventually posted after which there

\footnotetext{
${ }^{1}$ There were limited exemptions from liability, such as ministers of religion and those subject to an official mental health order.

${ }^{2}$ Since conscription covered the years 1949 to 1960 and since the age of eligibility was 18 to 26 years, then the birth cohorts 'at risk' would be expected to cover the years from 1923 to 1942 . In this case, why do we concentrate on the 1930 to 1939 cohorts? In the early years of conscription, the overwhelming majority of age groups posted to the services were in their teens. Thus, for the initial two intake years, 1949 and 1950, $51 \%$ of those posted were aged 18 and $36 \%$ aged 19 . Only $6 \%$ were aged $20,6 \%$ aged $21,1 \%$ aged 22 and none were posted aged 23 or over. Effectively, therefore, 1930 marked the first birth year from which significant numbers were called up. Full details are provided by Wallis (1977, pp. 97-99 and Table 11). In the last years of conscription, the position is even more clear cut. New postings applied to those born before $1^{\text {st }}$ October 1939. This premature end of call-up occurred because the government concentrated on clearing a large accumulated backlog of men whose call-up had been earlier deferred. This policy decision forms an important aspect of the current paper.
} 
was an almost unbroken decline. By the 1938 birth cohort, which was the last full birth year of conscription eligibility, $40 \%$ of males were posted.

What accounts for the differences in the proportion conscripted within each birth cohort as we move down column (1)? They stem from variations in the per-cohort contributions of two major categories of individuals. First, there were individuals who for a number of reasons were simply not posted. Second, there were individuals who were registered for conscription, who had their postings deferred and who were subsequently not posted.

The 'not posted' proportions by birth cohort are shown in column (2). Averaged over all cohorts, this category accounted for $35 \%$ of males. About half of these, comprising $17 \%$ of males over all birth cohorts, were officially declared to be medically unfit. This percentage exhibited a modest rising trend over most of the period ${ }^{3}$. The remainder of the 'not posted' category consisted, primarily, of those volunteering for armed service ${ }^{4}$ and those who were available for conscripted armed service but not actually posted. This latter group was not quantitatively important until the last three birth cohorts. New postings within these cohorts were strongly affected by the official

\footnotetext{
${ }^{3}$ While there were only $13 \%$ judged to be medically unfit from the 1930 cohort, this climbed to $17 \%$ for the 1931 cohort and then rose gradually to $20 \%$ for the 1937 and 1938 cohorts. The percentage fell to $10 \%$ for the 1939 cohort in line with the fact that conscription applied only to those born before $1^{\text {st }}$ October of that birth year. Wallis (1977, pp. 85-87) offers some explanations for these trends, mainly linked to changes in the composition, expertise and autonomy of the Medical Boards that undertook the medical examinations.

${ }^{4}$ Voluntary service offers an important factor behind the jump in the column (2) proportions in 1933. This coincided with a rise in the numbers recruited into the regular army between 1951 and 1955. For details, see Wallis (1977) Chapter 4 and Table 13.
} 
policy of prioritizing postings to the accumulations of earlier deferments thereby significantly reducing call-up based on new registrations. Since voluntary armed service had started to decline among the 1937-1939 birth cohorts, the 'available but not posted' category provided an increasingly large share of the proportions within the last cohorts in column (3). By the 1939 cohort, they accounted for roughly $75 \%$ of those not posted.

The 'deferred and never posted' proportions by birth cohort are shown in column (3). They accounted for $13 \%$ of males over all cohorts. Up to 1936 , this category comprised about $10 \%$ of each birth cohort. Thereafter, the percentage grew steeply in successive years $-14 \%$ in $1937,22 \%$ in 1938 and $27 \%$ in 1939 . In columns (4) - (6), we break down the proportions in column (3) into three sub-groups - viz. training/ education, essential occupations ${ }^{5}$, and hardship ${ }^{6}$. Deferment linked to training or education, shown in column (4), was dominated by (a) apprentices and so-called learners who were undertaking practical training leading to professional qualifications, and (b) students who were studying for university and other higher educational qualifications. $^{7}$ These two types of deferment accounted for a large part of the

\footnotetext{
${ }^{5}$ Individuals working in essential jobs, mainly in relation to post-war reconstruction, had their call-up deferred. Jobs in coal mining and farming were the two largest sub-groups (see Wallis, 1977, p.181).

${ }^{6}$ Examples of deferment on hardship grounds include the long-term illness of a close relative, responsibility for the care of an elderly parent, and a need to make arrangements for carrying on a business or disposing of it.

${ }^{7}$ Over the whole period, there were equal numbers of apprenticeship and university deferments, 47,500 and 47,200 respectively. There were also 3,200 post-apprenticeship deferments. At the end of the period, however, deferments among apprentices exceeded those of university students. Within the 1939 cohort there were 33,200 apprenticeship deferments and 15,500 university student deferments.
} 
substantial end-period growth of the 'deferred and never posted' category in column (4). Deferment for occupation-related reasons, shown in column (5), was also an important constituent part of the 'deferred and never posted' category of individuals. However, unlike their training/education equivalents, this group exhibited relatively small variations in their shares over the birth cohorts. Column (6) shows proportions of deferments on grounds of hardship that were subsequently not posted. This is clearly the least important sub-group and, like training/education exhibits an upward movement among the last cohorts eligible for conscription. However, hardship grounds only accounted for $2 \%$ of the 1938 birth cohort compared to $11 \%$ for training and education reasons.

Why were there increased proportions of deferments-not-posted due to training and education in the final cohort years? It was almost certainly due to individuals calculating that extra years of training or education might enable them to avoid call-up completely. It was generally known by 1957 that conscription was unlikely to be continued beyond $1960^{8}$ and, in the event, National Service was discontinued at the end of that year. This suggests that those born in 1942 were eligible for call-up. In practice, due primarily to an emphasis on clearing the backlog of deferments, no one born in 1940 or 1941 or 1942 was conscripted (Wallis, 1977; see also Royle, 1986). So, men

8 The Government's intentions in respect of future conscription were revealed in 1957. Its short-run objective was to build up the regular army and not to continue with conscription beyond 1960. Plans were stated in a Command Paper, 'Defence: Outline of Future Policy' (Cmnd. 124, London, HMSO, 1957). (See also Ministry of Labour Gazette, April 1957, pp.123/4.) 
born in 1939 were the last to face conscription. In fact, the end of September 1939 marked the precise watershed. Those born on or after $1^{\text {st }}$ October 1939 did not have to register for National Service. ${ }^{9}$

The government's determination to deal with the accumulation of deferments meant that the conscription experience of the last eligible birth cohorts differed from earlier years. From column (7) we note that proportions posted on reaching conscription age had started falling significantly year-on-year from the 1935 cohort onwards, with the decline markedly accelerating from 1937 to 1939 . In contrast, the proportion of deferments that were eventually posted, shown in column (8), remained remarkably robust up to 1939 , at about one-third of each birth cohort. Due largely to the objective of reducing the accumulated pool of deferments, individuals below the age of 20 were not posted from the 1938 and 1939 cohorts. Accordingly, there was a significant rise in the average age of posting among the final cohorts, as shown in column (9).

The major conscription patterns are illustrated graphically in Figure 1. Postings by birth cohort were reasonably uniform in the earlier years of National Service. For each birth cohort up to 1936, over a half of the postings occurred among men aged 18 and 19. A steep decline in the third year within a given cohort was followed by a slight

\footnotetext{
${ }^{9}$ As explained by the Minister of Labour (Edward Heath) to the House of Commons [Hansard, National Service (Call-up), 14 December, 1959]. This was in line with an earlier stated policy intention. See, for example, the Command Paper 'Call up of men to the Forces, 1957-1960' (Cmnd. 175, London, HMSO, 1957). Those born in the third quarter of 1939 were the last called upon to register and this resulted in 7,500 men posted in the second half of 1960 [Hansard, National Service (Mr. lan Chalmers), 10 March 1961]. In total, 30,435 men born in 1939 were posted in 1960.
} 
increase among 21 year olds and then by a gradual decline for those aged 22 and above. The rise at age 21 was due, primarily, to postings following the completion of education or company training. From the 1937 cohort onwards, there were significant growth rates in postings by age cohort among the post- 20 year olds. In fact, the majority of postings from the latter cohorts occurred at age twenty and above.

\section{The costs and benefits of military conscription ${ }^{10}$}

Did National Service involve net long-term costs in respect of the civilian jobs market? The present study falls into the class of papers that compares post-service earnings of those who served in the military to the earnings of those who never served. Mangum and Ball (1989) summarise U.S. studies that adopt this dichotomy. Veterans who served in WWII and in the Korean conflict are found to have enjoyed an earnings premium of between 3 and $12 \%$. In sharp contrast, evidence in respect of Vietnam War service appears comprehensively to show that veterans earned significantly less than nonveterans, though with widely varying estimated differentials across the various studies. Excluding employer-provided training, Mangum and Ball's own work on men and women who enlisted in 1974 in the 'all volunteer' era find that transfer of skills from military training to civilian employment was as high as if skills had derived from civilian sources. Moreover, they find that those who received military training enjoyed higher earnings within 2 years of their return to civilian employment than those civilian trained individuals.

\footnotetext{
${ }^{10}$ Wallis (1977) provides extended evidence on several key points in this Section.
} 
In relation to compulsory British call-up in the immediate post-WWII era, we believe that, a priori, it is simply not clear whether the typical conscript was measurably advantaged or disadvantaged.

\section{Costs}

\section{(i) Losses of work experience and human capital}

One of the obvious potential costs faced by many conscripts was that, due to an 18 month or two-year service posting, they had to forego returns to civilian work experience at a critically early stage of career development. ${ }^{11}$ For some, conscription would also have resulted additionally in losses associated with the acquisition of firmspecific human capital and/or the depreciation of acquired capital.

Such human capital losses are maximised when there is no offsetting training or experience provided by the armed services of value to civilian life. Wallis (1977, pp. 130/1) reports that, from 1949 to $1960,38 \%$ of army conscripts joined the 'teeth' Arm (Infantry, Artillery and Armoured Corp) where firing rifles and guns were the most essential of their acquired skills. ${ }^{12}$

\footnotetext{
${ }^{11}$ It seems unlikely that such losses extended significantly beyond armed service since the post-war period of National Service coincided with relatively tight labour markets with abundant job openings. See, for example, the Ministry of Labour Gazette, May 1957, p. 158. It may have been the case, however, that low education-level conscripts, leaving school at 14 or 15, may have underperformed in the early jobs hierarchy given that they anticipated being called up. Wallis (1977, pp 161/2) quotes concerns expressed by the Minister of Education in 1954 along these lines.

12 In fact, the most desirable skills of an infantryman may have involved the acquisition of especially high human capital specificity. Field Marshall Lord Wavell itemised such skills as those of "a successful poacher, a cat-burglar and a gunman".
} 


\section{(ii) Adjustment costs}

There is some evidence that the return to civilian life after conscription involved adjustment costs as young men attempted to make the transition between two very different working environments. Hickman (2004, p.218) reports on a 1957 survey of 70 companies' experience of returning conscripts. Problems were reported of work motivation following spells in the services during which there was less demand on individuals' working time. Ferguson and Cunnison (1959) report on a study of 771 men who left school in Glasgow at the minimum age of 14 in 1947. Of these, 498 were called up for National Service (346 at age 18 and 152 at age 21 in order for them to complete their apprenticeship training) with the remaining 273 rejected as unfit on medical grounds. The interesting finding between the Service and non-Service groups is that men of 'good' or 'average' scholastic ability exhibited post-conscription reductions in undertaking skilled work from $64 \%$ to $50 \%$ while their equivalents who were rejected for conscription showed no change over the same period, at a constant $41 \%$.

\section{Benefits $^{13}$}

(i) Marketable skills and general experience provided by the armed services

For many conscripts, service in the armed forces involved training and experience of direct value in civilian work applications. Even in the infantry, the section of the army most removed from civilian working life, general training and work experience opportunities of use in post-army life were quite abundant (Forty, 1998, p.

\footnotetext{
${ }^{13}$ We are indebted to David French for supplying us with helpful details presented in this sub-section.
} 
165). In each infantry battalion only about half of the 800 men were earmarked for direct combat. By the end of WWII, a battalion included about 90 motor vehicles, ranging from motor cycles to 3 ton trucks, and needed drivers who were trained in basic maintenance. It included a pioneer platoon of about 30 men who were carpenters, plumbers, bricklayers. It also contained a signals' platoon who were trained to operate quite complex radio and telephone equipment. Beyond the infantry, in the remaining two-thirds of the army, the largest combat arms after the infantry were the Royal Artillery, Royal Armoured Corps, Royal Engineers and Royal Corps of Signals, the Royal Ordinance Corps, and the Royal Electrical and Mechanical Engineers. Unsurprisingly given their titles, all contained large numbers of soldiers classed as tradesmen who possessed a range of mechanical skills with wide applications.

(ii) Inter-personal skills and skill-matching

A large majority of conscripts had previously left school at age 14 or 15 without the basic qualification of a General Certificate of Education. ${ }^{14}$ For many, high levels of comradeship, loyalty, team effort and inter-group responsibilities associated with military service offered saleable attributes in post-army civilian working life. This may have represented especially significant value added when set against their low educational attainments. Moreover, this broadening of experience was further extended for many conscripts since they shared an almost equal likelihood with their

\footnotetext{
${ }^{14}$ See Wallis (1977, Table 18, p. 125) who shows that over $60 \%$ of conscripts fell into this category in the early 1950 s, over $50 \%$ in the mid-1950s, and over $40 \%$ in the late 1950 s. The decline was due to deferments of individuals for higher educational reasons that were subsequently called up.
} 
regular military counterparts of being posted in overseas theatres, predominantly in Europe and the Far East (see Wallis, 1977, pp. 139-42). As for leadership opportunities and responsibilities, Wallis calculates that, in the decade preceding the end of conscription, $16 \%$ of army conscripts gained promotion.

In the cases of conscripts with higher levels of training and education, the armed services could also add long-term value. From 1942 all recruits were given intelligence and aptitude tests. Job descriptions were drawn up so that men with given aptitudes could be posted to the appropriate jobs. The transition from test score to job placement involved a period of job training (as much as 30 weeks, for example, for posting to the Royal Corps of Signals). Men with university degrees were directed along one of several routes. From the outset, they were earmarked as potential officers and tested to determine their potential leadership qualities. If they passed the test then, after 6 months training, they would spend $12-15$ months as an officer, responsible for perhaps 30 men. Many who failed the test were posted to the Royal Army Education Corps where they had the opportunity to make use of university-acquired transferable skills in teaching numeracy and literacy. Men with science and engineering degrees were commissioned into one of the scientific corps where they could make direct use of their degrees. As for men with apprenticeships, the army and other services went to considerable lengths to make direct use of their acquired trade skills. ${ }^{15}$

\footnotetext{
${ }^{15}$ Sources for this paragraph, supplied to us by David French, are as follows. The National Archives (1947 to 1959): War Office (WO), Nos. WO 216/238; Millman (1993); WO 32/12382; Cox (1949); WO 163/98/ECAC/P(45)88; WO 163/98/ECAC/M(45)38; WO 163/107/M(48)36; WO 33/2661; W0 163/59/AC/P(52)16; WO 384/10; WO 384/30; WO $32 / 17657$.
} 


\section{Wage Data and Coverage}

The sources of our wage data are outlined briefly below. There are three common denominators. First, all wage measures embrace both full-time and part-time workers. Second, all wages are deflated by the Retail Price Index. Third, to avoid outliers, we exclude the top and bottom percentiles from each of the three wage distributions.

(a) New Earnings Survey Panel Data (NESPD)

The NESPD is a panel covering a random sample of $1 \%$ of the British workforce. It is an employer survey of individual-level data obtained from company payrolls. Estimation is based on the data from 1975 to 2001. Data are obtained from company payrolls with employers legally obliged to provide the information which refers to a given week in April of each year. Accordingly, there is a high response rate. Statistics refer, principally, to earnings and hours of work and given they are taken directly from payroll records they are considered to be very accurate. This paper makes use of the basic or standard weekly wage, defined in the NESPD as "gross weekly earnings excluding overtime divided by normal basic hours for employees whose pay for the survey period was not affected by absence". Estimation was also undertaken using 
hourly wage earnings (including overtime) to replace standard hourly wages but this produced no substantive changes.

(b) General Household Survey (GHS)

The GHS is a continuous national survey of people living in private households, conducted on an annual basis by the Office for National Statistics (ONS). It started in 1971 and has been carried out since then, except for breaks in 1997-1998 when the survey was reviewed and in 1999-2000 when the survey was redeveloped. Unlike NESPD, the GHS is not a panel but rather a set of repeated cross-sections. Being a household survey, it is subject to non-response and reporting error. The average response rate for the GHS during the periods incorporated here is $82 \%$ and it exhibits very little year-to-year variation. The weekly earnings data in the GHS are probably inferior to NESPD due to mis-reporting, non-response, and changes over time in the exact definition of earnings. We make use of the $1979-1993$ surveys. $^{16}$

\section{(c) UK Family Expenditure Survey (FES)}

The FES is a voluntary survey of a random sample of private households in the United Kingdom carried out by ONS. It is a survey of household income as well as expenditures on goods and services. It started in 1957 with the purpose of providing information on spending patterns in the UK for use in the Retail Price Index. There is

\footnotetext{
${ }^{16}$ Pre-1979 the GHS survey adopts different earnings measurements than later periods. We do not use GHS data from 1994 onwards because (a) that year marks a switch from recording data by calendar to financial year (April to following March), and (b) the survey was not conducted in 1997.
} 
about a $60 \%$ response rate. Data are collected throughout the year to cover seasonal variations in expenditures. We use data from 1982 to 1993. Prior to 1982, hourly earnings data include overtime hours but these are excluded in later years.

Sample coverage

Our main reported RDD results cover data samples for birth years that are \pm 10 years of the 1940 pivotal birth year in respect of the conscription dummy. Thus, estimates of the wage effects of post-war National Service are based on samples of males born between 1930 and 1950. We also show results based on narrower intervals on either side of the discontinuity. The regressions also refer to individuals within the age-range of 25 to 55 . Haider and Solon (2006) show that in the U.S. current income is a reasonable proxy for lifetime income for men between their mid-30's and late 40's. To reflect this, we replaced the 25-55 age band with a 35-50 band. Results are shown with respect to both age bands.

\section{Estimation and Results}

We adopt a regression-discontinuity design (RDD), first introduced by Thistlethwaite and Campbell $(1960)^{17}$, to evaluate the real wage effects of the introduction of male conscription. In Section 2, we established that the probability of being treated - i.e. the probability of being posted into the armed services - changed discontinuously around a precise cut-off point. In 1939, males born before $1^{\text {st }}$. October - i.e. the first three quarters of that year's cohort- were the last who were obliged to

${ }^{17}$ Imbens and Lemieux (2008) and Lee and Lemieux (2009) provide up-to-date developments and discussion. 
register. However, both our first- and second-stage regressions - incorporating, respectively, proportions posted by year of birth and average real wages by year of birth as dependent variables - are based on annual data. Therefore, we have to impose the break at 1 January 1940 rather than $1^{\text {st }}$ October, 1939. Below, we outline an alternative estimation procedure that helps us to check on the sensitivity of measuring the break with a three month lag.

Utilising the data presented in Table 1, we estimate a first-stage regression in which the change in the imposition of conscription is used as an instrumental variable for the proportion of conscripts posted into the armed services. The addition of a quadratic in birth cohort allows for smooth changes in outcomes through time. As advised by Lee and Lemieux (2009) we also allow for the slope of the regression lines to differ on either side of the conscription discontinuity.

More explicitly, we define a conscript variable (CONSCRIPT) that takes the value 1 for those born before 1940 and 0 for those born in 1940 onwards. Then the first-stage regression takes the form

(1) POSTED $_{i}=\alpha_{0}+\alpha_{1}$ CONSCRIPT $_{i}+f\left\{Y_{\text {OOB }}-1940\right\}+$ CONSCRIPT $_{i} * f\left\{Y_{i}-1940\right\}+\varepsilon_{i}$

where $i$ indexes cohort, POSTED $i$ is the proportion posted into the armed services from the $i^{\prime}$ th cohort, $Y O B_{i}$ is year of birth, $f\left\{Y O B_{i}\right\}$ is a quadratic function of year-of-birth ${ }^{18}$,

\footnotetext{
${ }^{18}$ The facts that, in our setting, the forcing variable (year of birth) is discrete by nature and the regression function is fitted separately on both sides of the discontinuity means that the polynomial approximation can only be of relatively low order to preserve reasonable degrees of freedom. Our conclusions are, however, robust to using a cubic rather than a quadratic function of year-of-birth (see footnotes 22 and 23).
} 
and $\varepsilon_{\mathrm{i}}$ is an error term. The coefficient $\alpha_{1}$ measures the 1940 discontinuity in the fraction of individuals who were posted into the armed services. The specification allows the polynomial function to differ for pre- and post-1940 cohorts. This feature is especially important here. As shown in the upper graph of Figure 2, which contains the polynomial fit for the fraction of men posted in the armed forces by year of birth, the post-war conscription pattern is flat and equal to 0 . In estimating (1), we use weights equal to the number of males in each birth cohort level and compute robust standard errors (Lee and Card, 2008).

The reduced form specification in the second-stage of the estimation procedure employs the same structure as equation (1). The dependent variable is comprised of the hourly real wages of both full-time and part-time individual workers. Letting the log of the real straight-time hourly wage of the $i$ 'th cohort be represent by $\ln W_{i}$, we have (2) $\ln W_{i}=\beta_{0}+\beta_{1}$ CONSCRIPT $_{i}+f\left\{Y_{\text {OOB }}-1940\right\}+$ CONSCRIPT $_{i} * f\left\{Y_{i} B_{i}-1940\right\}+v_{i}$ The coefficient $\beta_{1}$ measures the effect of the 1940 discontinuity on the wage. ${ }^{19}$ Given that the dependent variable is based on individual-level observations while the righthand-side variables consist of single annual observations, we obtain (robust) standard errors by clustering at birth cohort level (Lee and Card, 2008).

\footnotetext{
${ }^{19}$ The precise constructions of our wage variables from the three data sources are summarized in Table 2. We have verified that replacing the basic hourly wage from the NESPD with weekly earnings (that include the effects of overtime) makes no substantive difference to the results.
} 
As stated earlier, annual data on postings and wages preclude us from incorporating October $1^{\text {st }}, 1939$ as the precise break-point for conscription. This forces us to lose some statistical power. By having to focus on the January $1^{\text {st }}, 1940$ as the break-point means that the discontinuity amounts to about 20 percentage points while the true pre/post October $1^{\text {st }}$ is closer to $30 \% .{ }^{20}$ We adopted an alternative strategy in an attempt to tackle this problem. We excluded individuals born in 1939 from the samples used to estimate (1) and (2). The main advantage of this approach is that it allows us implicitly to extrapolate the $1930-38$ polynomial fit to 1939 thereby yielding a jump of about $30 \%$. This is shown in the lower graph of Figure 2. An offsetting disadvantage is that this strategy is likely to reduce the precision of the estimates. In other words, it involves a trade-off between the increased statistical power of the larger discontinuity in the conscription pattern and the weaker precision of the pre reform polynomial fit.

Data for the first stage regression are obtained from Wallis (1977- see Table 1) while the second stage data relate to the NESPD, GHS and FES sources. Therefore, estimating the impact of military conscription on wages by computing the local average treatment of conscription - i.e. the impact of conscription on those who were 'forced' to take up service because they were born before 1940 - is obtained using Two Sample Two Stage Least Squares (TS2SLS) (Angrist and Krueger, 1992; Inoue and Solon, 2006). Since we are using one instrument in an exactly identified specification, the TS2SLS

20 If we split the 1939 cohort into two distinct groups, the probability of men born in the first three quarters of the year being posted is $24.6 \% / 0.75=32.8 \%$ while the probability of men born in the last quarter being posted is zero. 
estimator is the reduced form effect of conscription divided by the first stage effect. In terms of equations ( 1 ) and (2) this return is given by $\hat{\gamma}_{1}=\hat{\beta}_{1} / \hat{\alpha}_{1}$ with the standard error estimated using the delta method.

The results in this section are based on age bands of \pm 10 years on either side of the discontinuity. Based on the NESPD, our strongest data set, Figure 3 presents the polynomial fits for the pre- and post- 1940 data points. The fitted line is obtained by regressing the real wage averages on a birth cohort quadratic polynomial and an indicator for the end of adult post-war conscription in respect of the 1940 birth cohort, allowing the slopes to differ on both sides of the 1940 cutoff. We also show the equivalent graphs for females. In the event, both graphs indicate that, at best, the breaks appear to be very small.

Table 2 presents the first-stage, reduced form, and TS2SLS estimates of the male conscription effects. The results distinguish between those incorporating a 1940 discontinuity and those excluding individuals born in 1939. Additionally, we include estimates based on both the 25-55 and 35-50 age cohorts as well as augmented reduced form and 2SLS specifications that include the wage survey year and a quadratic in age. ${ }^{21}$

The first-stage estimates are shown in column (1) of Table 2. In line with Figure 2, they show that, at the 1940 breakpoint, there was a conscription discontinuity of 21\%. If we drop the 1939 cohort, the comparable estimate is $32 \% .{ }^{22}$ Columns (2) - (4)

\footnotetext{
${ }^{21}$ Which amounts to us including a quartic term in age rather than age and age-squared.

${ }^{22}$ Although they are less precisely estimated, the first stage coefficients are of the same order of magnitude when we use a cubic rather than a quadratic function of year-of-
} 
show the reduced form effects of the ending of conscription on the log of hourly real wage rates. Across all three data sets - by both estimation strategies, and by differing age and wage specifications - there are no significant jumps in male real wages at the conscription discontinuities. ${ }^{23}$ Columns (5) - (7) contain the same regression specifications but this time showing the 2SLS estimates of the effect of postings on hourly earnings. All estimates are again insignificantly different from zero. Essentially, all outcomes are consistent with the graphical illustration in the top half of Figure 3.

\section{Robustness checks}

We carry out three robustness checks.

\section{(a) Females}

Females were excluded from post-war conscription. If there were no conscription effects for males, we would expect to obtain equivalent results for females if we estimated wage equation (2) 'as if' women were conscripted. Since there are clearly no equivalent first-stage data for females, we can only show the reduced form female equation (2) estimates. Table 3 reports our findings. ${ }^{24}$ In general, and in line with

birth: the estimate is 0.14 (significant at the $5 \%$ level) when individuals born in 1939 are included and 0.35 ) (significant at the $10 \%$ level) when they are excluded.

${ }^{23}$ The reduced form estimates are also not significantly different from zero when we use a cubic rather than a quadratic function of year-of-birth.

${ }^{24}$ The NESPD under-reports individuals who earn less than the Pay As You Earn (PAYE) tax threshold in Britain. This is not a problem with male data but is more serious in the case of females. Accordingly, we re-weight the NESPD female data so as to be in line with GHS where this problem does not occur. Since the FES has slightly higher proportions of females below the threshold, we also re-weighted this series to conform 
the equivalent male reduced forms in Table 2, we obtain no significant estimates in respect of the discontinuity. ${ }^{25}$ We also note from the graphical illustrations in Figure 3 that the male and female fitted polynomial plots appear to be very similar.

\section{(b) Differing age bands}

We checked on the sensitivity of the Table 2 results to the introduction of differing male age ranges on either side of the discontinuity. We show two of these in Table 4, for \pm 7 years, and \pm 5 years using the NESPD and the 1940 discontinuity. Our earlier conclusion that there is no significant break remains unchanged. The results reflect all those obtained using the GHS and FES as well as all results omitting individuals born in 1939.

\section{(c) Schooling and training effects}

In Section 2 we pointed out that deferred postings among those undertaking post-school education and training rose considerably towards the end of the conscription period. From Table 1, column (4), we see that this was a growing phenomenon for those born in the years 1935 to 1939. The obvious inference is that, given it was known as early as 1957 that conscription was likely to end by 1960 , there was a take-up of more apprenticeships and higher education places due to attempts to avoid ultimate call-up. One unintended consequence of such action would be to increase the take-up of education and training among men compared to women (Card

to the GHS. For more discussion on this issue see Hart (2009a). In the event, reweighting makes little difference to the results obtained.

${ }^{25}$ With one exception in the case of women aged 25-55, using the FES with survey year and age controls, and dropping the 1939 cohort. 
and Lemieux, 2001; Maurin and Xengogiani, 2007). In particular, Maurin and Xengogiani show that the abolition of military conscription in France lowered the average educational achievement of males by removing the incentive to enrol into education with the aim of postponing conscription. Looked at from a different perspective, this can be viewed as an indirect 'benefit' of military service in that it provides an offset to aggregate losses in work experience.

From the viewpoint of our RDD design, this type of behaviour raises an important question. Did the end of National Service in Britain induce a discontinuous drop in the average educational attainment of the post-conscription cohorts of males? There are two possibilities resulting from such a drop. In the first place, the RDD estimates may be reflecting not only the direct costs and benefits of military service outlined in Section 3, but also its indirect effects on education and training choices. Our finding of zero earnings effects could then be consistent with a positive effect of conscription on education but a negative effect on work experience. In the second place, military service may have to some extent increased the provision of post-school education because of the impact of the avoidance/postponement factor. It is clearly important to check whether or not a discontinuity occurred in the evolution of average educational attainment around the cut-off point and, therefore, whether our RDD estimates may have been contaminated by such an educational component. To this end, we carried out two types of investigations. 
First, we used the Labour Force Survey (LFS) to examine graphically male and female evolutions of education and training variables. ${ }^{26}$ The sample was restricted to individuals born in the UK from 1930 to 1950 and aged 25-64 at the time of the survey. Specifically, we examine the evolutions of these cohorts by (a) ages leaving full time education by males and females, (b) proportion of males completing an apprenticeship, and (c) proportions of males and females completing a first or higher degree.

Figure 4 compares the average age that males and females left full time education by year of birth. The graphs exhibit no particular 1939/40 discontinuity for males - as would be expected if a significant proportion of males started higher education courses in an attempt to avoid conscription - and, moreover, shows that the abolition of military conscription did not reduce the average educational attainment of males with respect to females. As a refinement, we compared the evolution of the fraction of individuals who left full-time education at age 19 or above for males and females. Again, the graphs displayed no obvious 1939/1940 break around the discontinuity.

Figure 5 shows the proportion of males who reported having completed an apprenticeship. ${ }^{27}$ This graph shows very clear evidence of both a rise in the fraction of males completing an apprenticeship among the last cohorts of conscripts (1938 and

\footnotetext{
${ }^{26}$ Specifically, we made use of the 1979-1991 annual LFS and the 1992-1999 quarterly LFS to create a dataset which contains the following harmonized variables: year of birth, age, sex, country of birth, age left full-time education, completion of apprenticeship, and highest qualification held.

27 Female equivalents are not shown: less than $6 \%$ of females completed apprenticeships over these birth cohorts.
} 
1939) and then a drop after the abolition of the military service for individuals born from 1940 onwards. It is therefore in line with the deferments figures discussed in Section 2. Notwithstanding this observation, it is probable that the impact of this source of avoidance/postponement factor on our estimates is negligible. First, the drop in the fraction of males having completed an apprenticeship was spread over several cohorts rather than immediately and in fact the 1939/1940 discontinuity is quite small. Second, the potential problem is significantly reduced in our estimates that exclude the 1939 cohort from the samples (see Table 2) since we note that Figure 5 reveals very similar proportions of males having completed an apprenticeship in the 1938 and 1940 cohorts.

Finally, in Figure 6, we examine the evolution of the proportions of males and females holding a higher education or degree qualification. ${ }^{28}$ In contrast to apprenticeships, these graphs show no evidence of a drop in the proportion of males (relative to females) holding a higher education qualification after 1939. The postponing/avoidance story hence seems to have been driven mainly by apprenticeships. This seems consistent with the fact that in the final years of military conscription, more deferments were granted to apprentices than to university students (see footnote 6).

Our second approach to investigating possible impacts of education and training at the conscription discontinuity involved RDD estimation based on the annual LFS data.

\footnotetext{
${ }^{28}$ These cover a higher degree, first degree, diploma in higher education, teaching qualification (further education, secondary, primary, foundation stage), nursing qualification, as well as several other higher education diplomas below degree level.
} 
Using birth cohorts from 1933 to $1947^{29}$ we estimated, for males and females

separately, the following equation:

(3) FTED $_{i}=\gamma_{0}+\gamma_{1}$ CONSCRIPT $_{i}+f\left(Y_{i}-1940\right)+$ CONSCRIPT $_{i} * f\left(Y_{i}-1940\right)+\eta_{i}$

where FTED is average age left full-time education. Also using LFS, we substituted APPRENT, the proportion completing an apprenticeship, and HIGHED, proportion with a higher educational or degree qualification. Using each of the three dependent variables separately for males and females in the age range $25-61$, we obtained $\hat{\gamma}_{1}^{\prime} s$ that are insignificantly different from zero using either education variables. Results are reported in Table 5.

\section{The end of National Service and deferred postings: a cautionary note}

As we have seen, by the end of the period all postings consisted of deferments. Thus, while those born in 1942 were notionally eligible to be conscripted in 1960 (i.e. the final year of National Service) new call-ups of 18 year olds ended at the end of the third quarter of 1939. In an earlier working paper (Hart, 2009) and in Buonnano (2007), no adjustment was made for deferments in the RDD. Results obtained are interesting

\footnotetext{
${ }^{29}$ The start cohort year, 1933, is chosen so that we avoid complications related to the effects of compulsory schooling reforms in 1947. On $1^{\text {st }}$ April 1947, the minimum school leaving age was raised by law from 14 to 15 . The fraction leaving school before 15 fell from over $60 \%$ for the 1932 birth cohort to about 10\% for the 1934 cohort (see Devereux and Hart, 2010).
} 
because, while erroneous, they appear to be much more consistent with the prevailing view that spells of military service significantly impair future real earnings for cohorts eligible for conscription compared to subsequent cohorts.

What if we re-set the discontinuity in the CONSCRIPT variable and the year of birth functions in equation (2) to 1943 ? Figure 7 shows the resulting graphical illustrations. Now the discontinuity in wages around the 1943 cut-off appears to be significantly negative for males eligible for conscription compared to subsequent cohorts. By contrast, there appear to be no significant difference for females. These outcomes are confirmed by the reduced form estimates based on equation (2). ${ }^{30}$ This is seemingly in line with negative long term pay effects of conscription on male labour market outcomes compared to their non-applicability for females.

While we know that these estimates are misleading, because no postings were in fact made after 1939, it is nonetheless interesting to investigate what lies behind the findings. The likely answer relates to the need to test for jumps at non-discontinuity points in RDD (see Imbens and Lemieux, 2008, Section 7.3). Note from the male graph in Figure 7 that an outlying point occurs at the 1945 birth cohort. A possible explanation of this relates to the baby boom which peaked immediately after the war. Figure 8 shows the number of British male births from 1930 to 1950 and the very close matches of the NES-based birth cohorts. The immediate post-war baby boom, peaking in 1946/7, is clearly evident. So what happens if we arbitrarily now set the discontinuity in equation

\footnotetext{
${ }^{30}$ Based on the NESPD, the estimates (standard errors) of $\beta_{1}$ in equation (2) using a 1943 discontinuity are: men, -0.019 (0.006); women, -0.012 (0.012).
} 
(2) to 1946, which lies near the peak of the boom? We see from Figure 9 that the pre1946 male cohorts, in sharp contrast to setting the discontinuity at 1943, appear to enjoy a higher wage trajectory than subsequent cohorts, although the reduced form estimates now give somewhat weaker support. ${ }^{31}$

If we set the discontinuity at 1946 , it is hard to judge whether the resulting male polynomials in Figure 9 fit the data better or worse than the comparable plots in Figure 7. But, unlike 1943 , the period around 1946 offers a potentially strong explanation for the RDD outcomes. The labour market was relatively tight throughout the late $1950 \mathrm{~s}$ and 1960s. Male industrial labour supply rose very significantly in the early 1960 s as a result of the baby boom cohorts entering the labour market for the first time. The male discontinuity in Figure 9 may be indicating that this enhanced labour supply served to depress the unit price of labour services. In terms of conscription effects, it also incidentally served to produce spurious 1943 outcomes. ${ }^{32}$

\section{Conclusions}

We argue that it is difficult to make definitive judgements as to net costs and benefits of male military conscription. In the event, and based on a regression

\footnotetext{
${ }^{31}$ Again based on the NESPD, the estimates (standard errors) of $\beta_{1}$ in equation (2) using a 1946 discontinuity are: men, 0.014 (0.005); women, 0.002 (0.009).

${ }^{32}$ One possibility is that the effects near to 1945 simply derive from the changing characteristics of the sample. Using our most accurate data source, the NESPD, we checked both wage and employment patterns by birth year from 1935 to 1955 in respect of each year of the NESPD data (i.e. 1975 to 2001). We found no irregularities around 1945.
} 
discontinuity design, we find no evidence that post-war male military conscription in Britain had an effect on the long-term real earnings of eligible birth cohorts.

Perhaps there are special reasons why immediate post-war conscription produces these findings. Compared to more recent decades, the 1950s and 1960s offered young men and women far fewer higher education and training opportunities and far more limited social mobility. A majority of the conscripts discussed here left school at 14 or 15 without basic qualifications. For many, compared to their expected experiences in the absence of National Service, military conscription would have served to broaden their horizons on several important fronts. They had to mix with cross sections of individuals drawn from a wide variety of social, educational, and locational backgrounds. They were expected to provide cooperative team effort. They enjoyed relatively high degrees of geographical mobility, both national and international. A significant number were promoted and required to take on leadership roles. Many future prospective employers in the civilian jobs market are likely to have been positively influenced by the attributes acquired through this experience when making their hiring decisions. Averaged across all serving conscripts, these gains could well have offset the losses associated with the negative impact of conscription on civilian work experience. 


\section{References}

Angrist, J D. 1990. Lifetime earnings and the Vietnam era draft lottery: evidence from social security administrative records. American Economic Review 80, 313-336.

Angrist, J D.1998. Estimating the Labour Market Impact of Voluntary Military Service Using Social Security Data on Military Applicants. Econometrica 66, 249-88.

Angrist, J and A B Krueger. 1992. The effect of age at school entry on educational attainment: and application of instrumental variables with moments from two samples, Journal of the American Statistical Association 87, 328-36.

Angrist, J and A B Krueger. 1994. Why do World War II veterans earn more the nonveterans? Journal of Labor Economics 12, 74-97.

Bauer, K, S Bender, A R Paloyo and C M Schmidt. 2009. Evaluating the labor market effects of compulsory military service. IZA Discussion Paper 4535.

Buonanno, P. 2007. Long-term effects of conscription: lessons from the UK. Mimeo, University of California, Berkeley and University of Bergamo.

Card D and T Lemieux. 2001. Going to College to Avoid the Draft: the Unintended Legacy of the Vietnam War. American Economic Review 91(2), 97-102.

Cox, C F. 1949. The selection of officers. Army Quarterly 58, 229-32.

Devereux, P J and R A Hart. 2010. Forced to be rich? Returns to compulsory schooling in Britain. Economic Journal (forthcoming).

Ferguson, T and J Cunnison. 1959. The impact of National Service. British Journal of Sociology 10, 283-290.

Forty, G. 1998. British Army Handbook 1939-1945. Stroud, Glouc. 
Haider, S and G Solon. 2006. Life-cycle variation in the association between current and lifetime earnings. American Economic Review 96, 1278-1296.

Hart, R A. 2009(a). Did British women achieve long-term economic benefits from working in essential WWII industries? IZA Discussion Paper \# 4006.

Hart, R A. 2009(b). Above and beyond the call. Long-term real earnings effects of British male military conscription during WWII and the post-war years. IZA Discussion Paper \# 4118.

Hickman, T. 2004. The call up: a history of National Service 1947-1963. London: Headline Book Publishing Ltd.

Imbens, $\mathrm{G}$ and T Lemieux. 2008. Regression discontinuity designs: a guide to practice. Journal of Econometrics 142, 615-635.

Imbens, $\mathrm{G}$ and $\mathrm{W}$ van der Klaauw. 1995. Evaluating the cost of conscription in the Netherlands. Journal of Business and Economic Statistics 13, 207-215.

Inoue, A and G Solon. 2006. Two-sample instrumental variable estimators. Working Paper.

Lee, D S and D Card. 2008. Regression discontinuity inference with specification error. Journal of Econometrics 142, 655-674.

Lee, D S and T Lemieux. 2009. Regression discontinuity designs in economics. NBER Working Paper 14723. 
Mangum S and D Ball. 1989. The Transferability of Military-Provided Occupational Training in the Post-Draft Era. Industrial and Labor Relations Review 42(2), 230245.

Maurin, E and T Xenogiani. 2007. Demand for Education and Labor Market Outcomes. Lessons from the Abolition of Compulsory Conscription in France. Journal of Human Resources 42(4), 795-819.

Millman, C. 1993. Stand Easy or the Rear Rank Remembers. Edinburgh: Pentland Press. Parker, H.M.D. 1957. Manpower: a study of war-time policy and administration. London: Longman, Green and Co.

Royle, T. 1986. The years of their lives. The National Service Experience 1945-63. London: Michael Joseph.

Wallis, L J. 1977. Peacetime conscription and the British army. M.Litt. Thesis, University of Lancaster.

Thistlethwaite, D.L. and D.T. Campbell. 1960. Regression-discontinuity analysis: an alternative to the ex post facto experiment. Journal of Educational Psychology $51,309-317$. 


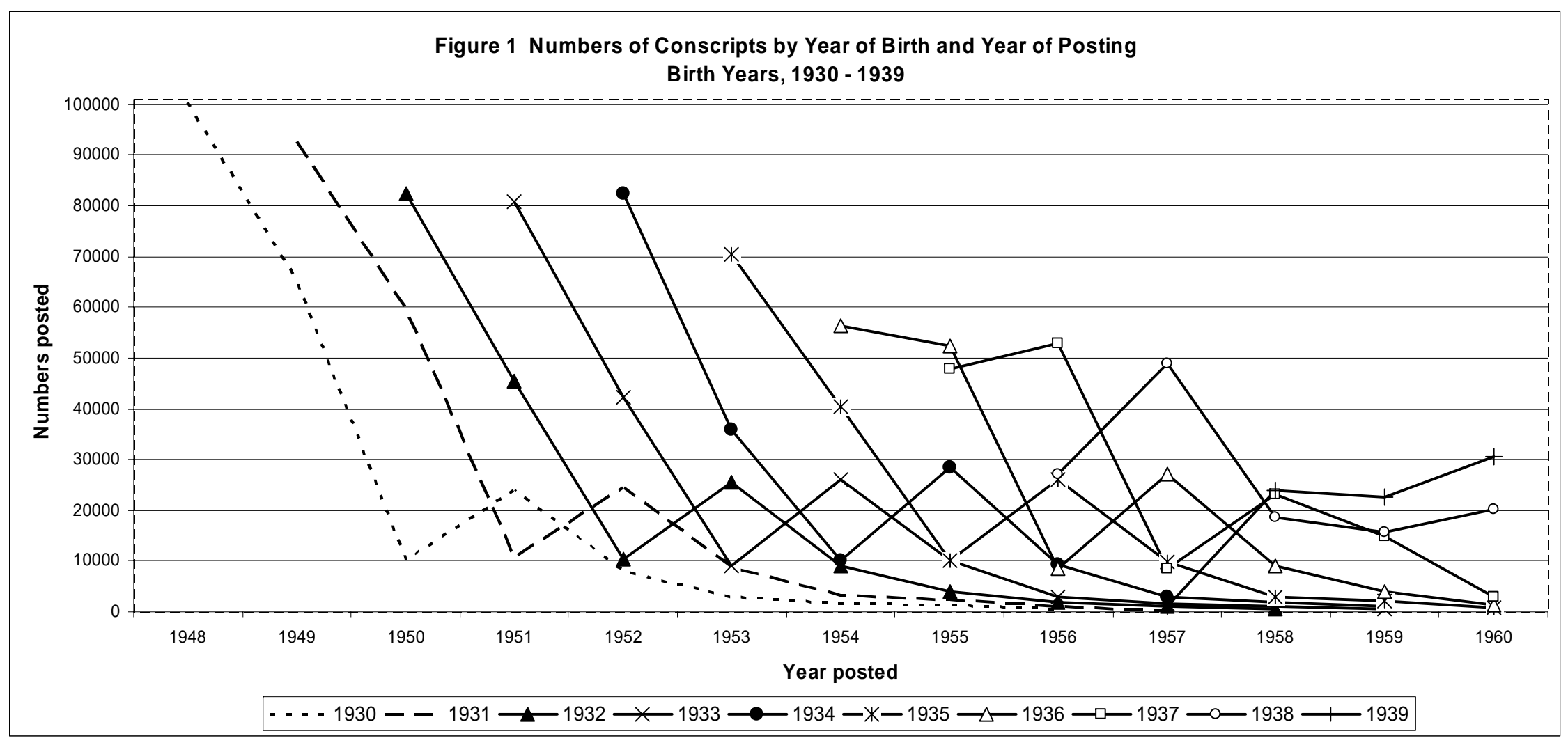

Source: Based on data obtained from Wallis (1977, p. 198, Appendix Table 26) 
Figure 2 Proportion of men posted into the armed forces by year of birth
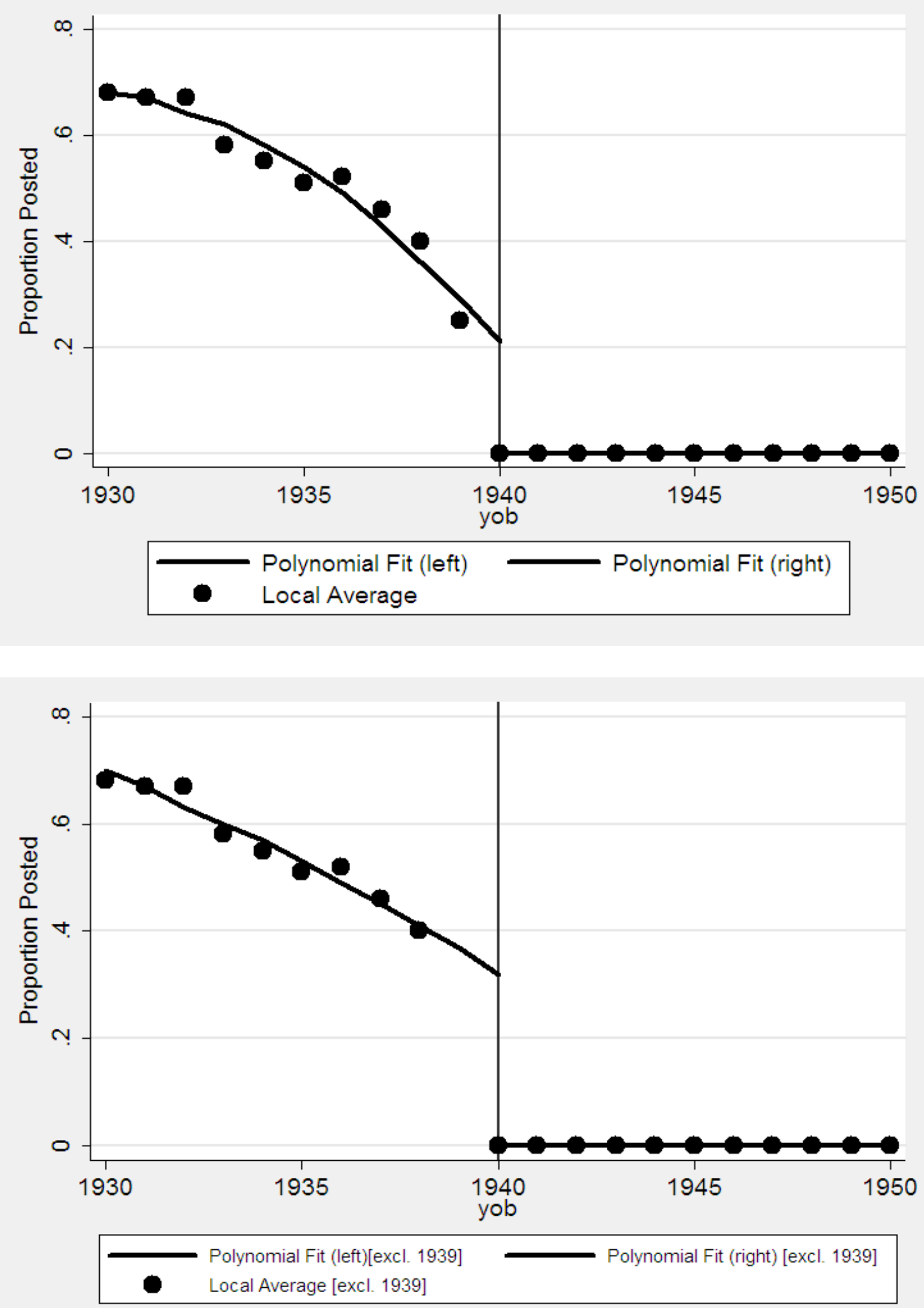
Figure 3 Average hourly real basic pay of men and women aged 25 to 55 by 1930 to 1950 birth cohorts (NESPD)

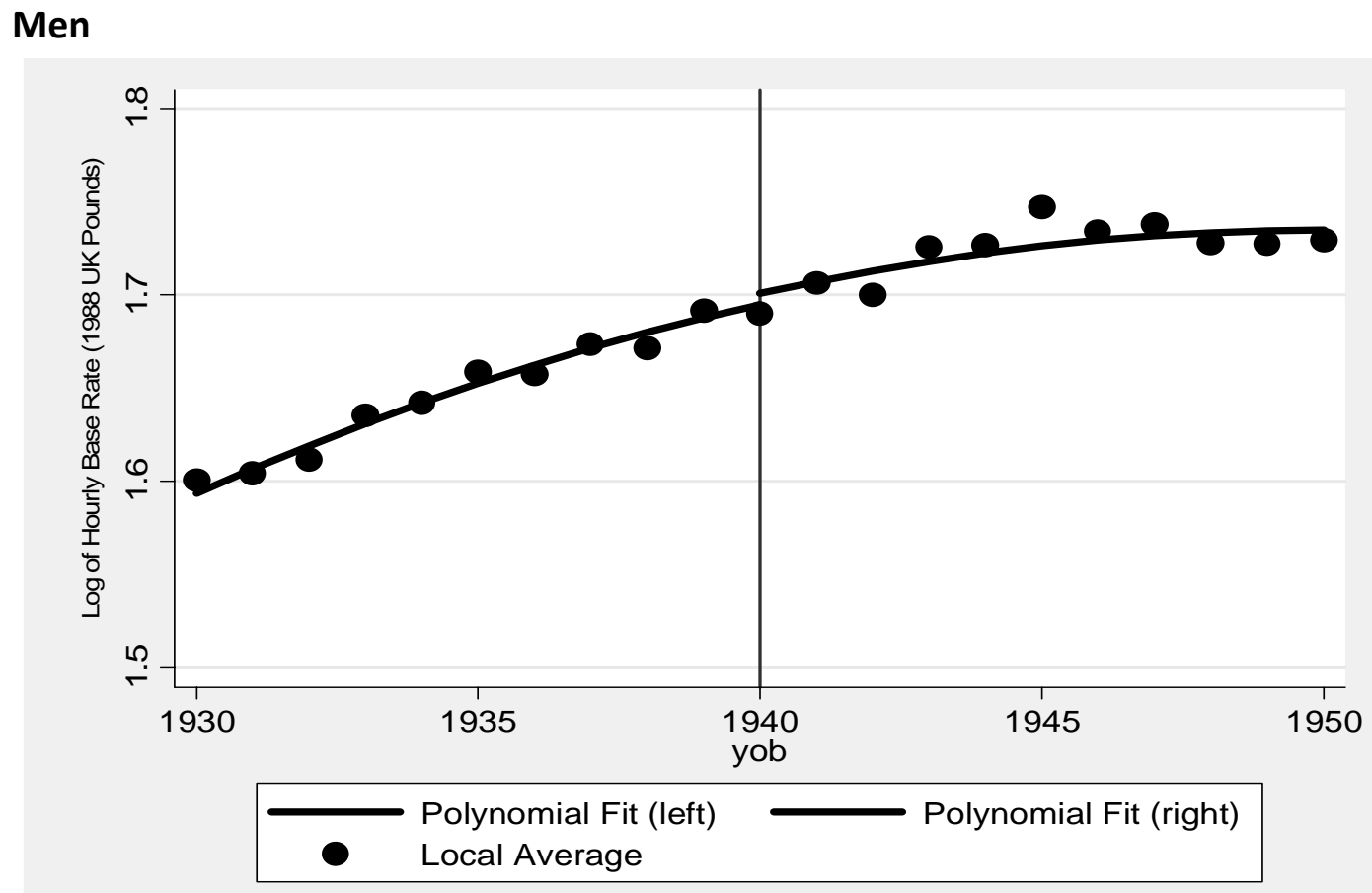

\section{Women}

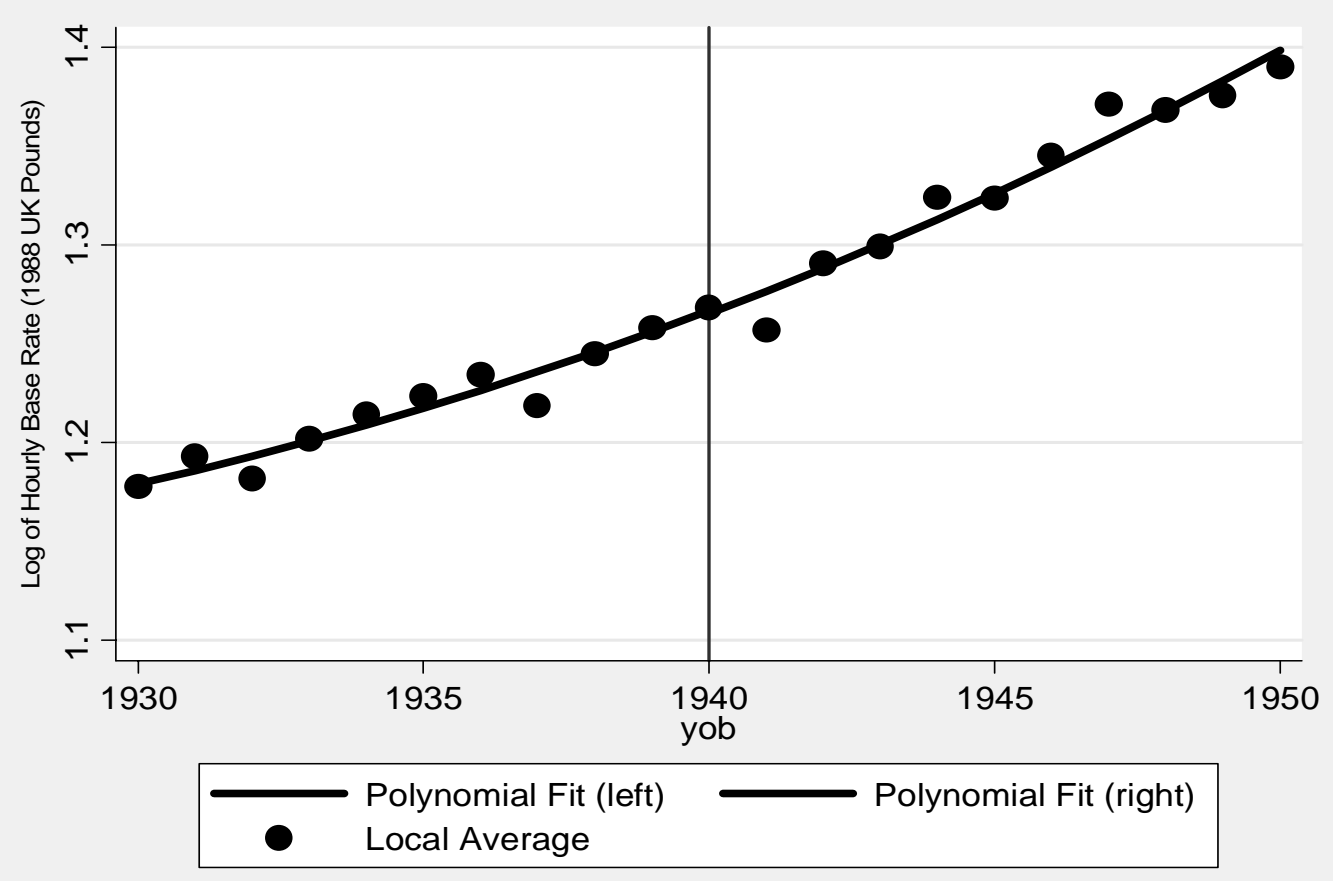


Figure 4 Average age left full-time education by birth cohort (LFS)

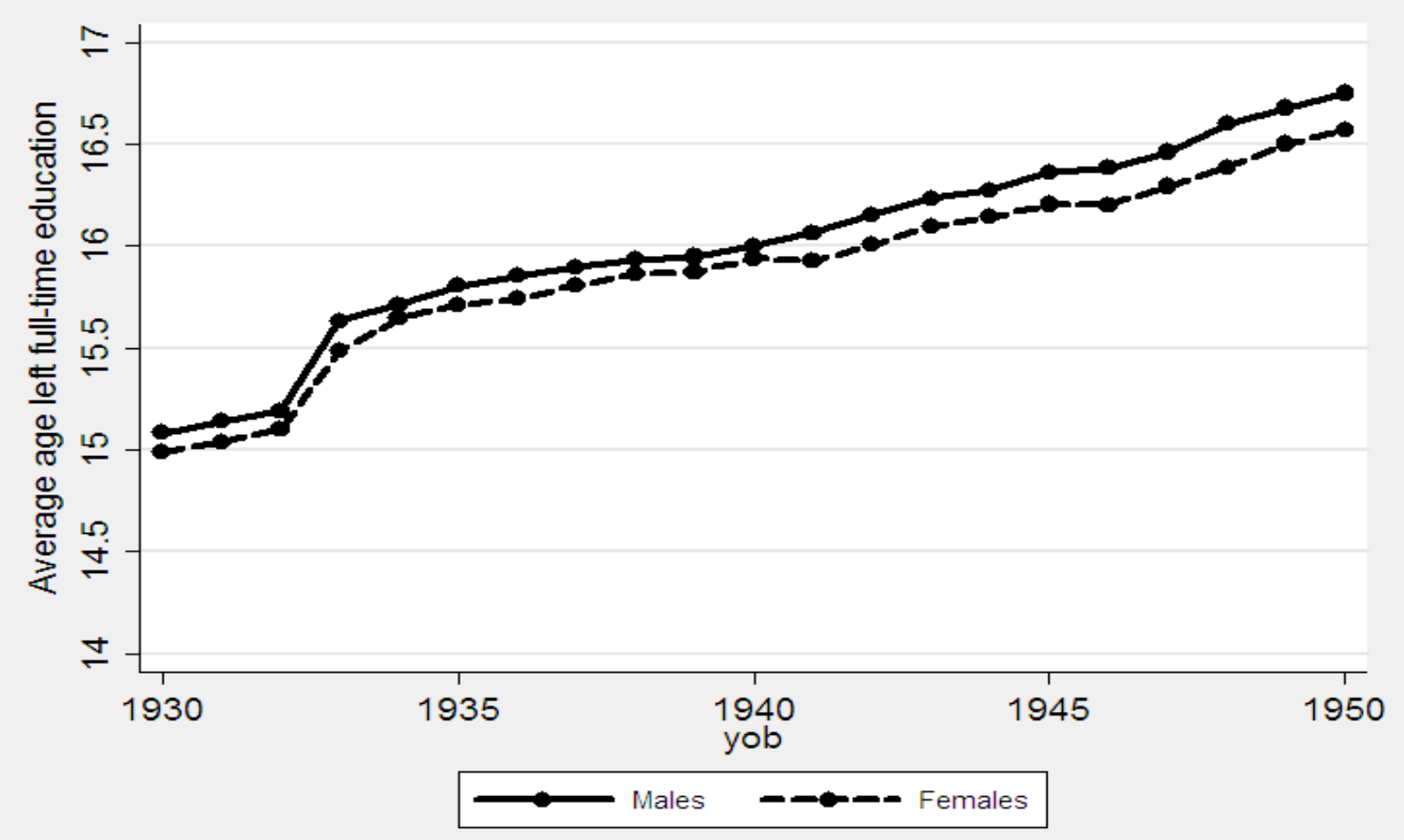

Figure 5 Fraction of males who completed an apprenticeship by year of birth (LFS)

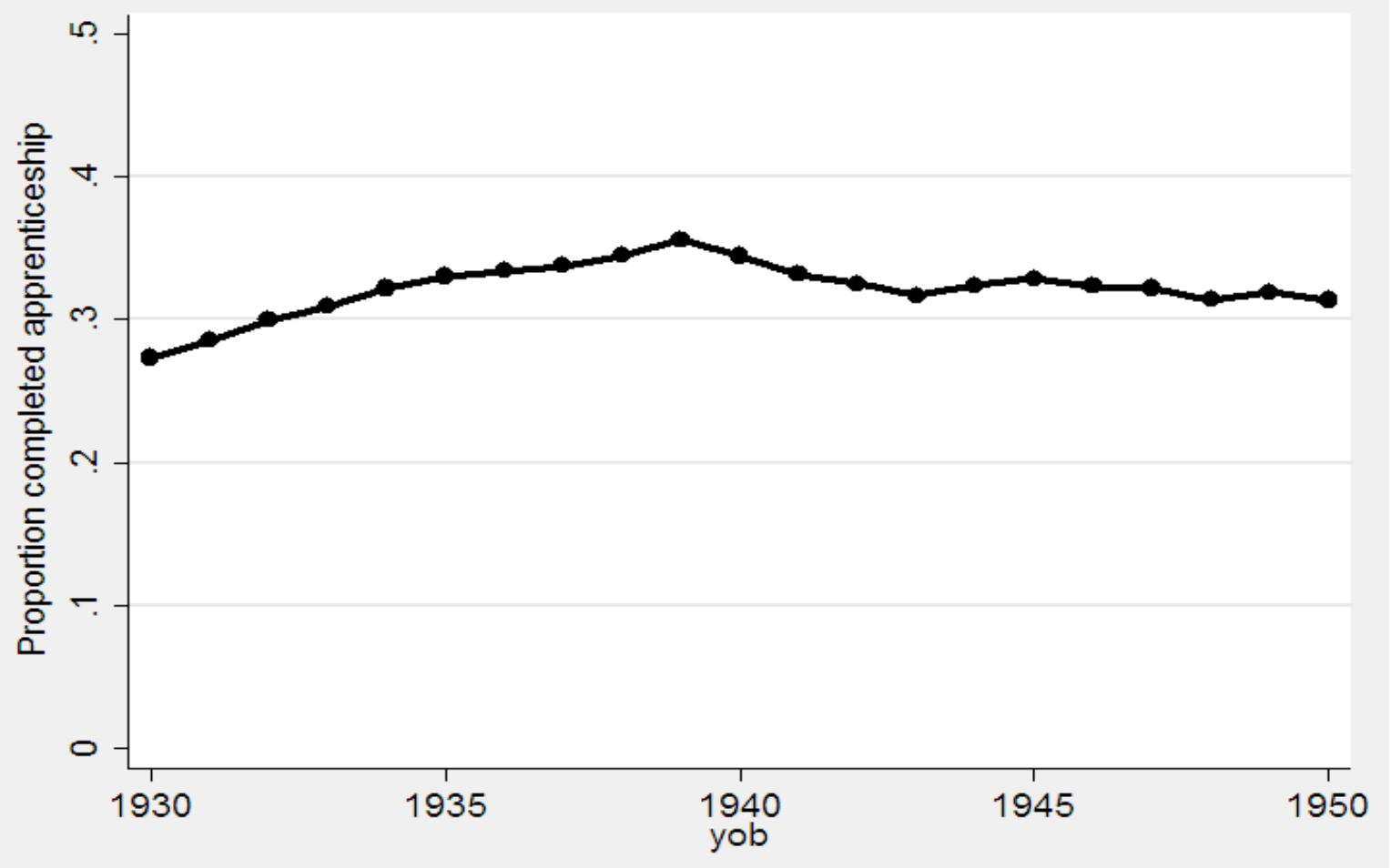


Figure 6 Proportion with a first or higher degree by birth cohort (LFS)

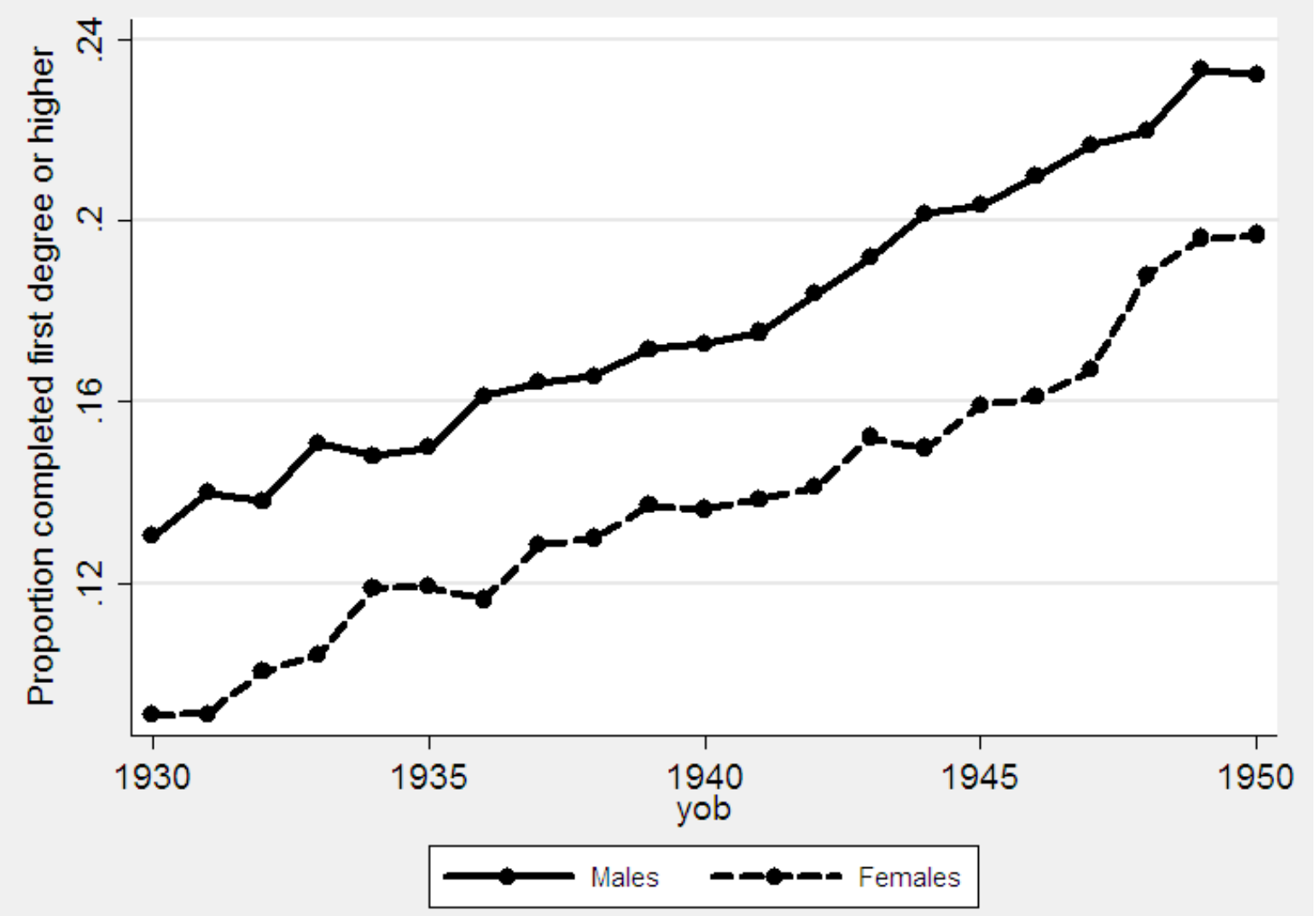


Figure 7 Average hourly real basic pay of men and women aged 25 to 55 by 1933 to 1953 birth cohorts (NESPD)

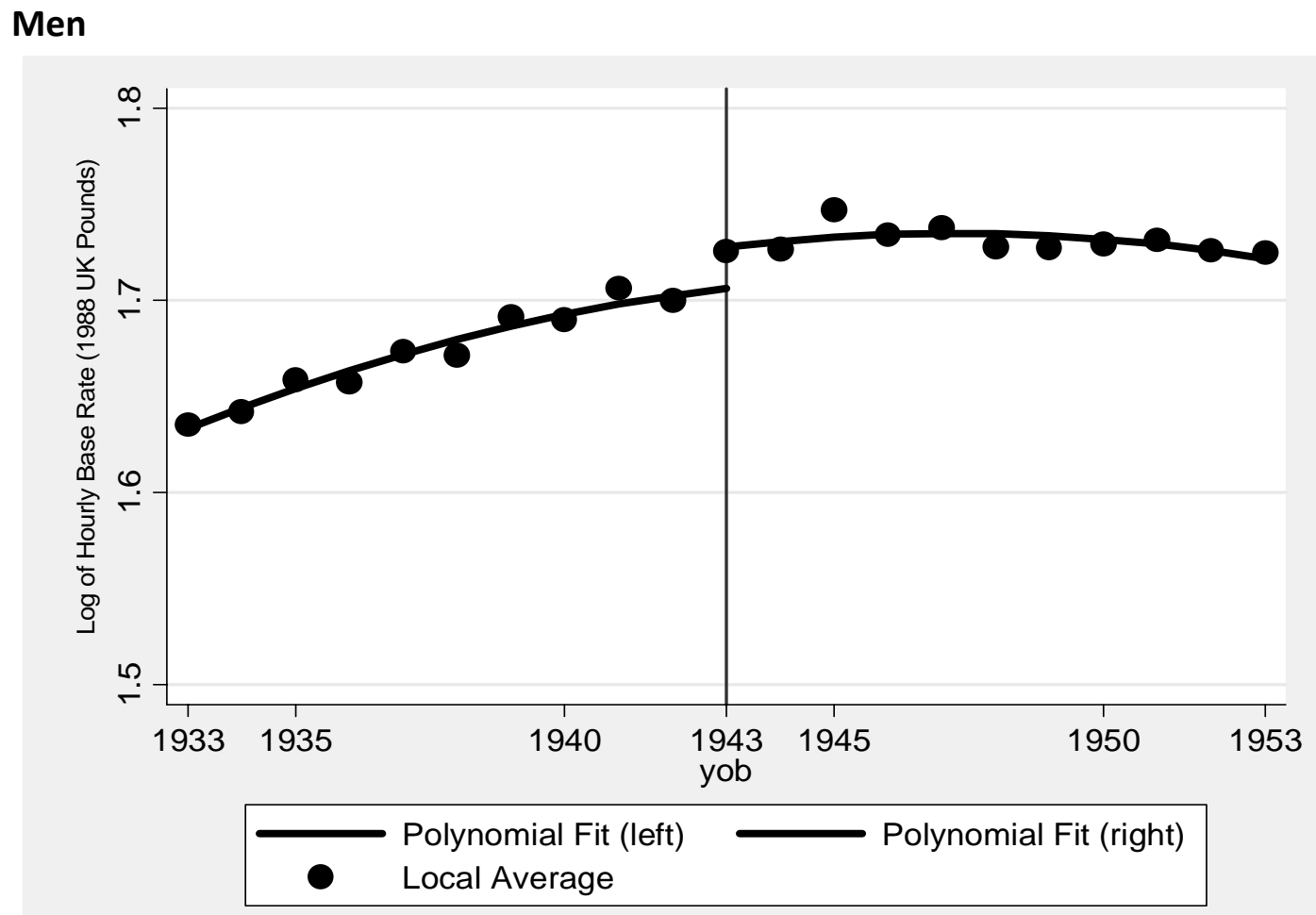

\section{Women}

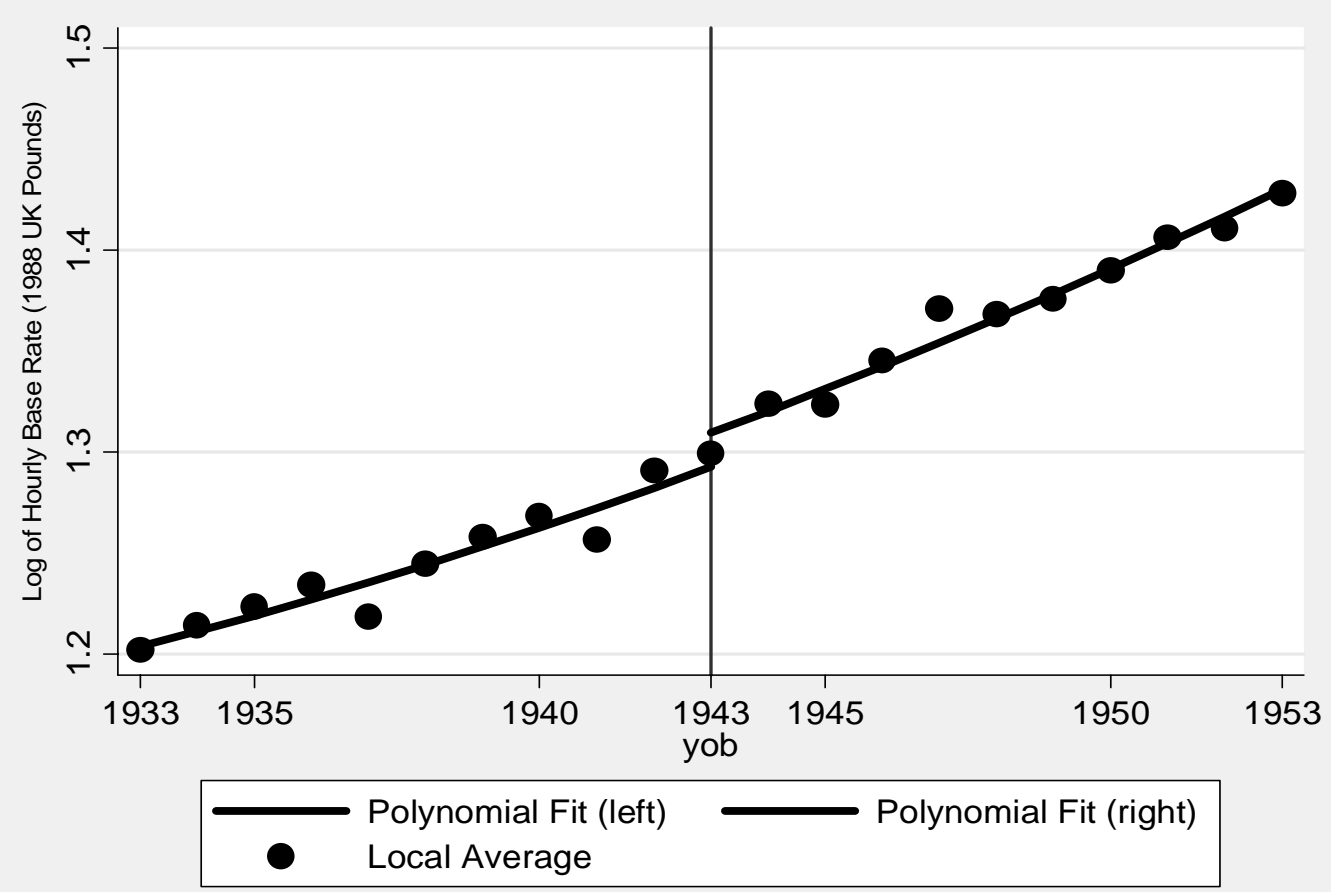


Figure 8 Male national birth rates ('000s) and corresponding rates from the NES sample

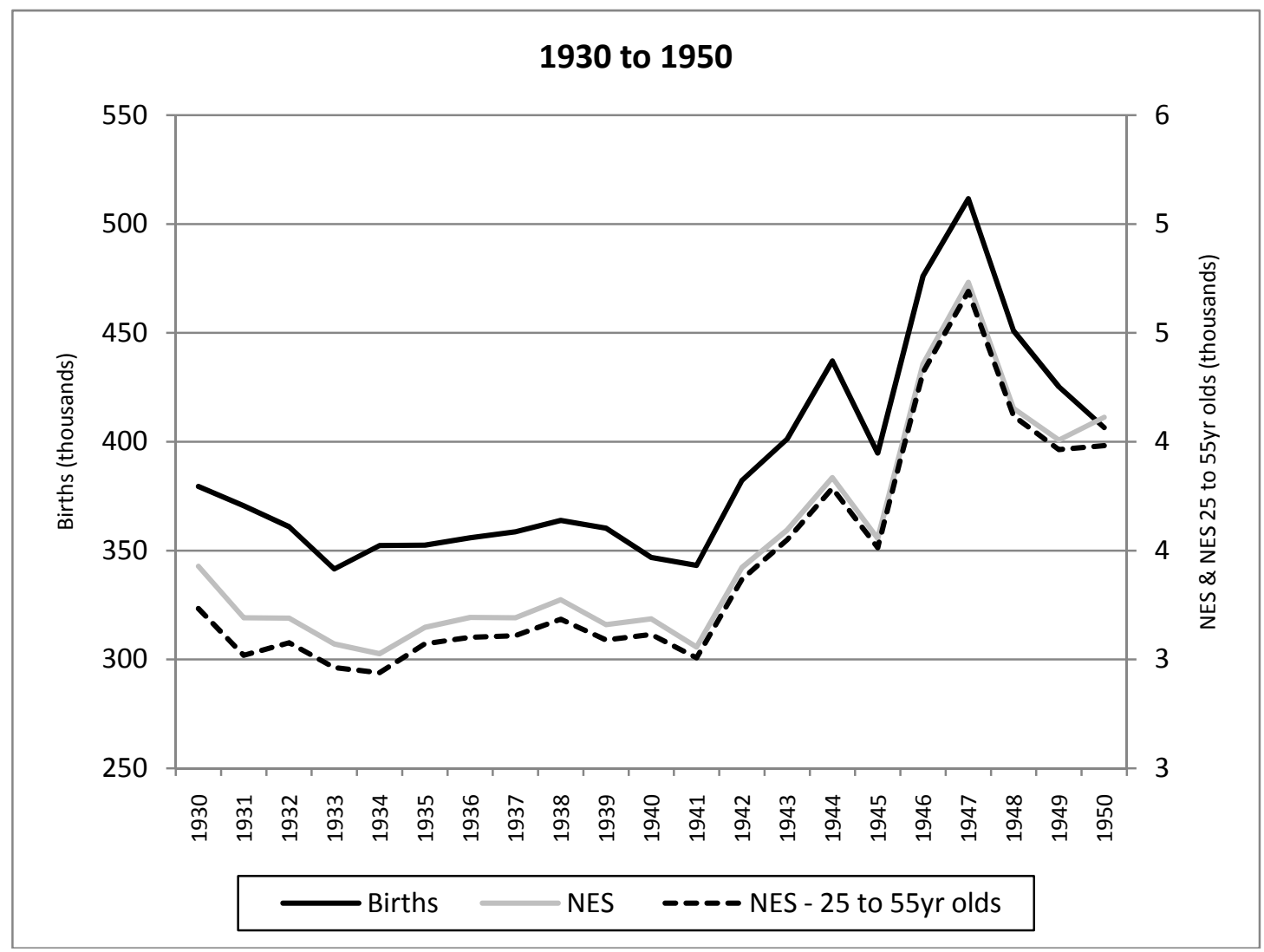


Figure 9 Average hourly real basic pay of men aged 25 to 55

by 1936 to 1956 birth cohorts (NESPD)

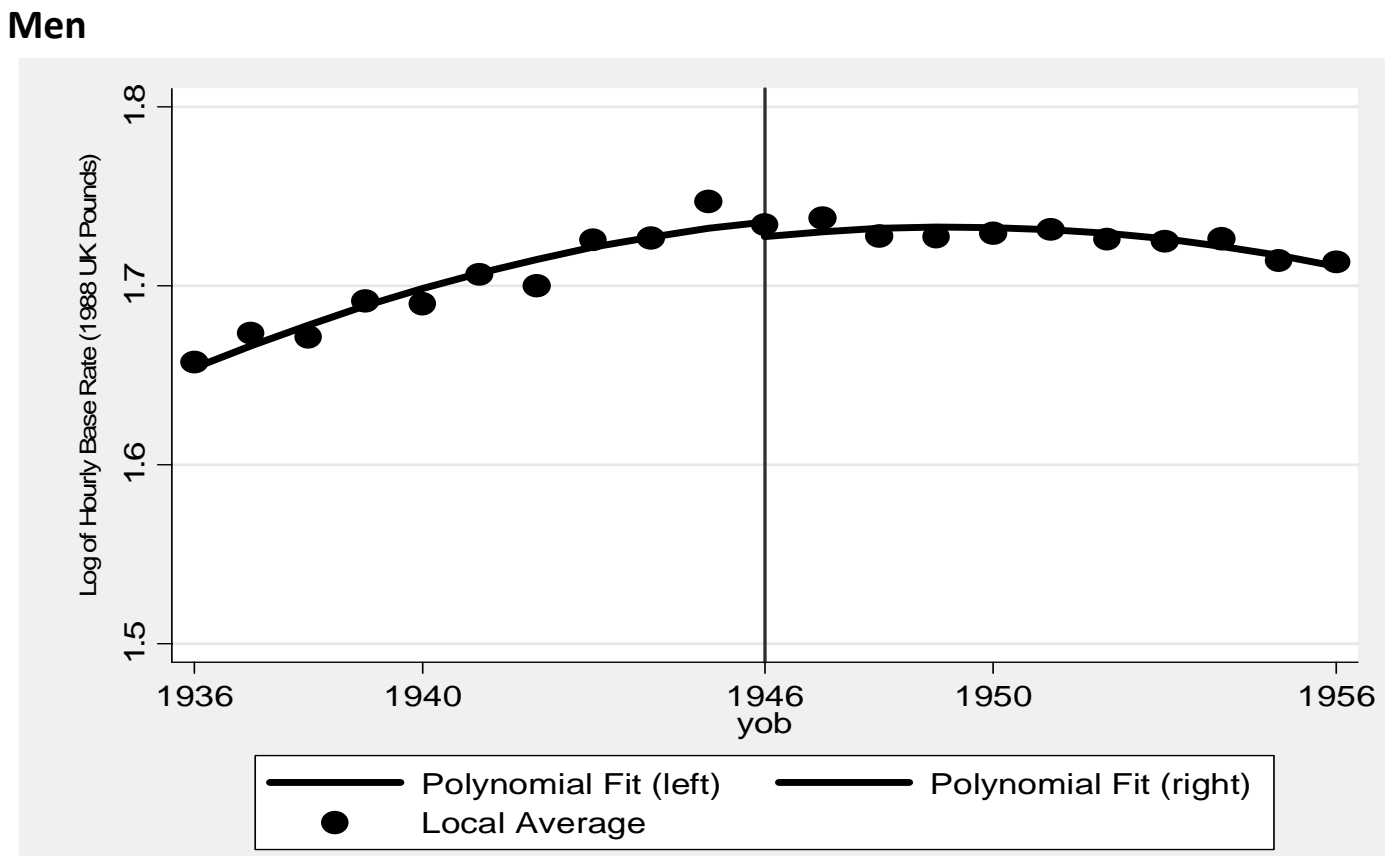

\section{Women}

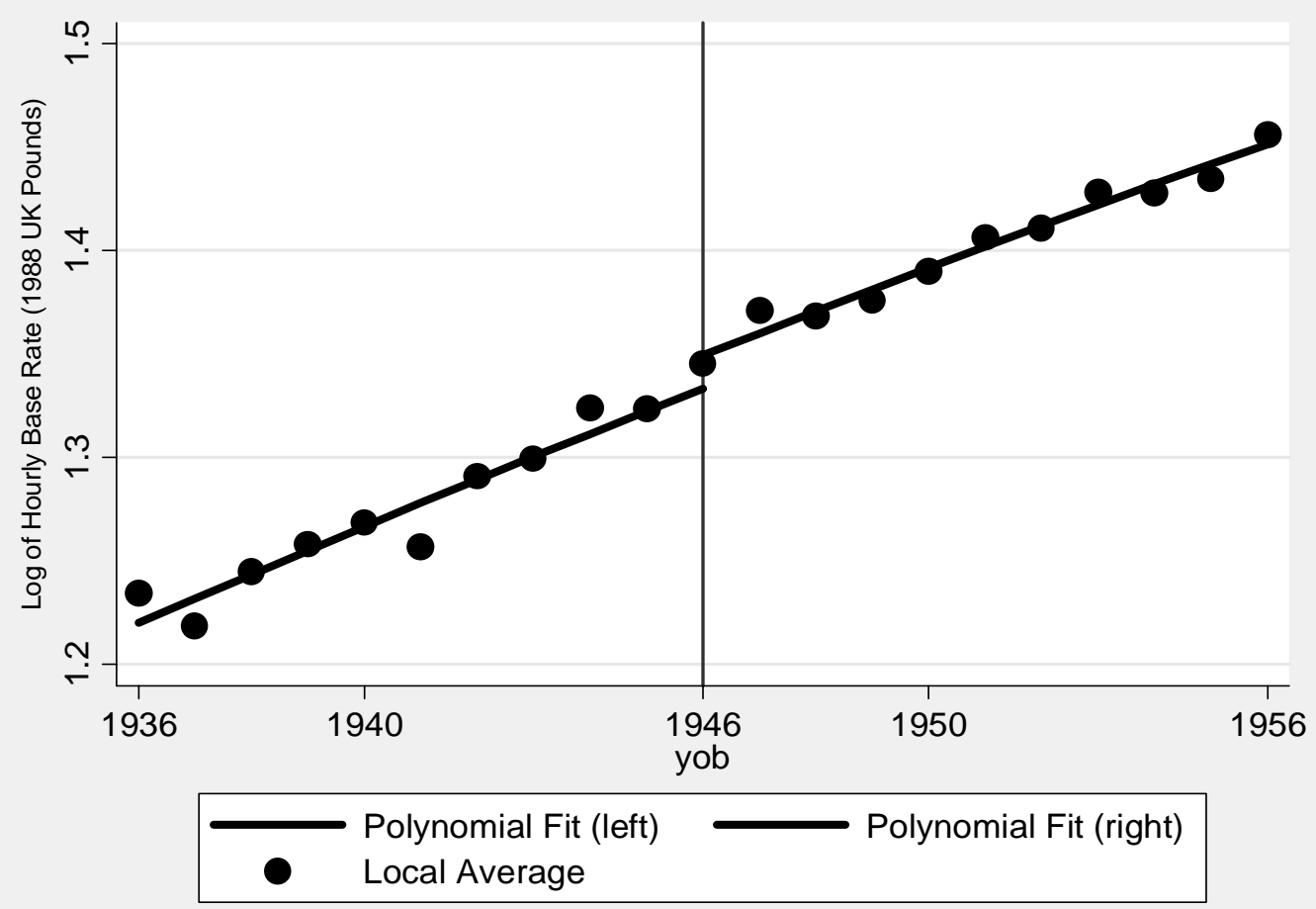


Table 1 Proportions of postings and deferred postings into the armed services by birth cohorts

\begin{tabular}{|c|c|c|c|c|c|c|c|c|c|}
\hline \multirow{2}{*}{$\begin{array}{l}\text { Year of } \\
\text { Birth }\end{array}$} & $\begin{array}{l}\text { Eventually } \\
\text { Posted }^{\mathrm{a}}\end{array}$ & $\begin{array}{c}\text { Not } \\
\text { posted }^{b}\end{array}$ & $\begin{array}{l}\text { Deferred and never } \\
\text { posted }^{c}\end{array}$ & \multicolumn{3}{|c|}{ Deferred and never posted by category ${ }^{d}$} & $\begin{array}{l}\text { Initially } \\
\text { posted }^{\mathrm{a}}\end{array}$ & $\begin{array}{c}\text { Eventually posted after } \\
\text { deferment }^{\mathrm{a}}\end{array}$ & $\begin{array}{c}\text { Average Age a } \\
\text { Posting }^{\mathrm{a}}\end{array}$ \\
\hline & (1) & $(2)$ & (3) & (4) & (5) & (6) & (7) & (8) & (9) \\
\hline 1930 & 0.683 & 0.228 & 0.089 & 0.001 & 0.086 & 0.002 & 0.320 & 0.362 & 19.06 \\
\hline 1931 & 0.671 & 0.232 & 0.097 & 0.002 & 0.092 & 0.003 & 0.305 & 0.366 & 19.14 \\
\hline 1932 & 0.674 & 0.215 & 0.111 & 0.003 & 0.104 & 0.004 & 0.309 & 0.365 & 19.22 \\
\hline 1933 & 0.578 & 0.353 & 0.069 & 0.001 & 0.063 & 0.004 & 0.268 & 0.310 & 19.23 \\
\hline 1934 & 0.554 & 0.367 & 0.078 & 0.003 & 0.070 & 0.005 & 0.266 & 0.289 & 19.24 \\
\hline 1935 & 0.506 & 0.404 & 0.090 & 0.012 & 0.073 & 0.005 & 0.219 & 0.287 & 19.30 \\
\hline 1936 & 0.517 & 0.374 & 0.108 & 0.027 & 0.076 & 0.006 & 0.201 & 0.316 & 19.28 \\
\hline 1937 & 0.461 & 0.397 & 0.142 & 0.053 & 0.080 & 0.008 & 0.147 & 0.314 & 19.41 \\
\hline 1938 & 0.402 & 0.382 & 0.217 & 0.109 & 0.088 & 0.019 & 0.083 & 0.319 & 19.64 \\
\hline $1939^{e}$ & 0.246 & 0.488 & 0.267 & 0.182 & 0.064 & 0.020 & 0.003 & 0.243 & 20.05 \\
\hline Average & 0.525 & 0.347 & 0.128 & 0.041 & 0.079 & 0.008 & 0.209 & 0.316 & 19.30 \\
\hline
\end{tabular}

a Obtained from Wallis (1977). b Medically unfit, awaiting medical examination, army service volunteers, available for armed forces but not posted. Obtained from Ministry of Labour Gazettes, (May) 1956, 1958, and 1960 - 'Numbers of men registered under National Service Acts'. c Source as in b. d Source as in b. e Proportions are calculated in respect of the whole birth year. This is in line with the preceding proportions. Note, however, that actual postings in 1939 involved only those born before $1^{\text {st }}$ October. 
Table 2 First-stage, reduced form and TS2SLS estimates of the effects of conscription on male I $1940 \pm 10$ years

\begin{tabular}{|c|c|c|c|c|c|c|c|}
\hline & \multirow{2}{*}{$\begin{array}{r}\begin{array}{c}\text { First } \\
\text { stage: } \% \\
\text { posted }\end{array} \\
(1)\end{array}$} & \multicolumn{3}{|c|}{$\begin{array}{l}\text { Reduced form: log hourly } \\
\text { earnings }\end{array}$} & \multicolumn{3}{|c|}{ TS2SLS: log hourly earnings } \\
\hline & & $(2)$ & (3) & (4) & (5) & (6) & (7) \\
\hline \multicolumn{8}{|l|}{ Wallis (1977): } \\
\hline $\begin{array}{l}\text { Including } 1939 \text { cohort } \\
(\mathrm{N}=21)\end{array}$ & $\begin{array}{l}0.213^{* *} \\
(0.035)\end{array}$ & - & - & - & - & - & - \\
\hline & $0.321 * *$ & - & - & - & - & - & - \\
\hline $\begin{array}{l}\text { Excluding } 1939 \text { cohort } \\
(\mathrm{N}=20)\end{array}$ & $(0.033)$ & & & & & & \\
\hline \multicolumn{8}{|l|}{ NESPD 1975-2001: } \\
\hline $\begin{array}{l}\text { Including } 1939 \text { cohort } \\
(N=713,668)\end{array}$ & - & $\begin{array}{c}0.007 \\
(0.007)\end{array}$ & $\begin{array}{c}0.006 \\
(0.007)\end{array}$ & $\begin{array}{c}0.005 \\
(0.007)\end{array}$ & $\begin{array}{c}0.034 \\
(0.035)\end{array}$ & $\begin{array}{c}0.028 \\
(0.035)\end{array}$ & $\begin{array}{c}0.023 \\
(0.034)\end{array}$ \\
\hline $\begin{array}{l}\text { Excluding } 1939 \text { cohort } \\
(N=683,149)\end{array}$ & - & $\begin{array}{l}-0.003 \\
(0.010)\end{array}$ & $\begin{array}{l}-0.005 \\
(0.008)\end{array}$ & $\begin{array}{l}-0.007 \\
(0.007)\end{array}$ & $\begin{array}{l}-0.008 \\
(0.031)\end{array}$ & $\begin{array}{l}-0.017 \\
(0.025)\end{array}$ & $\begin{array}{l}-0.021 \\
(0.023)\end{array}$ \\
\hline \multicolumn{8}{|l|}{ GHS 1979-1993: } \\
\hline $\begin{array}{l}\text { Including } 1939 \text { cohort } \\
(N=26,982)\end{array}$ & - & $\begin{array}{l}-0.005 \\
(0.011)\end{array}$ & $\begin{array}{l}-0.002 \\
(0.010)\end{array}$ & $\begin{array}{l}-0.009 \\
(0.011)\end{array}$ & $\begin{array}{l}-0.022 \\
(0.052)\end{array}$ & $\begin{array}{l}-0.011 \\
(0.047)\end{array}$ & $\begin{array}{l}-0.040 \\
(0.052)\end{array}$ \\
\hline $\begin{array}{l}\text { Excluding } 1939 \text { cohort } \\
(N=25,638)\end{array}$ & - & $\begin{array}{l}-0.018 \\
(0.023)\end{array}$ & $\begin{array}{l}-0.009 \\
(0.021)\end{array}$ & $\begin{array}{c}0.001 \\
(0.024)\end{array}$ & $\begin{array}{l}-0.056 \\
(0.072)\end{array}$ & $\begin{array}{l}-0.029 \\
(0.066)\end{array}$ & $\begin{array}{c}0.002 \\
(0.074)\end{array}$ \\
\hline \multicolumn{8}{|l|}{ FES 1982-1993: } \\
\hline $\begin{array}{l}\text { Including } 1939 \text { cohort } \\
(N=16,445)\end{array}$ & - & $\begin{array}{l}-0.019 \\
(0.014)\end{array}$ & $\begin{array}{l}-0.024 \\
(0.014)\end{array}$ & $\begin{array}{l}-0.030 \\
(0.018)\end{array}$ & $\begin{array}{l}-0.090 \\
(0.067)\end{array}$ & $\begin{array}{l}-0.115 \\
(0.069)\end{array}$ & $\begin{array}{l}-0.141 \\
(0.086)\end{array}$ \\
\hline $\begin{array}{l}\text { Excluding } 1939 \text { cohort } \\
(N=15,663)\end{array}$ & - & $\begin{array}{l}-0.012 \\
(0.025)\end{array}$ & $\begin{array}{l}-0.015 \\
(0.025)\end{array}$ & $\begin{array}{l}-0.021 \\
(0.040)\end{array}$ & $\begin{array}{l}-0.036 \\
(0.079)\end{array}$ & $\begin{array}{l}-0.048 \\
(0.077)\end{array}$ & $\begin{array}{l}-0.066 \\
(0.124)\end{array}$ \\
\hline \multicolumn{8}{|l|}{ Controls: } \\
\hline Survey year & No & No & Yes & Yes & No & Yes & Yes \\
\hline Quadratic in age & No & No & Yes & Yes & No & Yes & Yes \\
\hline Age range & - & $25-55$ & $25-55$ & $35-50$ & $25-55$ & $25-55$ & $35-50$ \\
\hline
\end{tabular}

*Significant at 5\%; ** significant at 1\%. Robust standard errors in brackets allow for clustering by year of birth. Coverage and construction of wage and earnings data are as follows:

NESPD, 1975-2001: wage = [basic weekly wage (excluding overtime)] / [normal basic weekly hours];

GHS, 1979-1993: earnings = [gross weekly earnings] / [weekly hours usually worked (excluding meals and overtime)];

FES, 1982-1993: earnings = [normal gross weekly wage] / [weekly hours usually worked (excluding meals and overtime)]. 
Table 3 Reduced Form effect of military conscription on female log real hourly wage rates. $1940 \pm 10$ years

\begin{tabular}{|lccc|}
\hline \multicolumn{3}{c|}{ Reduced form: log hourly earnings } \\
& $(1)$ & $(2)$ & $(3)$ \\
\hline & & & \\
NESPD 1975-2001: & & & \\
\hline Including 1939 cohort & 0.006 & 0.002 & 0.008 \\
(N = 509,483) & $(0.010)$ & $(0.010)$ & $(0.008)$ \\
Excluding 1939 cohort & 0.006 & -0.003 & 0.007 \\
(N = 487,275) & $(0.016)$ & $(0.016)$ & $(0.016)$ \\
& & & \\
GHS 1979-1993: & & & \\
Including 1939 cohort & 0.007 & 0.0003 & 0.011 \\
(N=24,947) & $(0.014)$ & $(0.013)$ & $(0.014)$ \\
Excluding 1939 cohort & 0.014 & -0.003 & -0.003 \\
(N=23,722) & $(0.028)$ & $(0.027)$ & $(0.025)$ \\
& & & \\
FES 1982-1993: & & & \\
Including 1939 cohort & 0.002 & -0.006 & -0.004 \\
(N = 14,691) & $(0.014)$ & $(0.015)$ & $(0.022)$ \\
Excluding 1939 cohort & -0.031 & $-0.041^{*}$ & -0.070 \\
(N = 13,965) & $(0.019)$ & $(0.016)$ & $(0.036)$ \\
& & & \\
\hline Controls: & & & Yes \\
Survey year & No & Yes & Yes \\
Quadratic in age & No & Yes & $35-50$ \\
Age range & $25-55$ & $25-55$ & \\
\hline
\end{tabular}

* significant at $5 \% ;{ }^{* *}$ significant at $1 \%$

The NESPD and FES wage data are re-weighted to conform to the GHS coverage. Compared to GHS, the NESPD under-reports females paid below the PAYE thresholds while the FES has slightly higher proportions than GHS below the thresholds.

Robust standard errors in brackets allow for clustering by year of birth.

Coverage and construction of wage and earnings data are as follows:

o NESPD, 1975-2001: wage = [basic weekly wage (excluding overtime)/normal basic weekly hours];

o GHS, 1979-1993: earnings = [gross weekly earnings/weekly hours usually worked excluding meals and overtime];

o FES, 1982-1993: earnings = [normal gross weekly wage]/ weekly hours usually worked excluding meals and overtime]. 
Table 4 Robustness check: reduced form estimate of the impact of military conscription on male log real hourly earnings. Effect of narrowing birth cohorts around the 1940 cutoff.

(NESPD)

\begin{tabular}{|lcc|}
\hline \multicolumn{2}{c|}{$\begin{array}{c}\text { Dependent Variable: log real hourly wage } \\
(1)\end{array}$} & $(2)$ \\
\hline Conscription dummy & 0.025 & 0.056 \\
& $(0.039)$ & $(0.032)$ \\
Observations & 512,305 & 360,138 \\
\hline Birth cohorts & & \\
Age range & $1940 \pm 7$ years & $1940 \pm 5$ years \\
& $25-55$ & $25-55$ \\
\hline
\end{tabular}


Table 5 Robustness check: testing for a discontinuity in average educational attainment of males and females around the 1940 cohort cutoff (LFS)

Dependent Variable: (1) average age left full-time education (FTED), (2) proportion completed apprenticeship (APPRENT), (3) proportion with a higher or first degree (HIGHED).

Males

$\begin{array}{lccc}\text { Conscription dummy } & -0.033 & 0.004 & 0.009 \\ & (0.022) & (0.008) & (0.005)\end{array}$

Females

Conscription dummy

0.022

0.002

0.005

(0.046)

(0.005)

(0.005)

Number of observations

Males

530,030

530,030

530,030

Females

443,868

443,868

443,868

Age range

25-64

$25-64$

$25-64$

Year of birth

1933-1947

1933-1947

1933-1947

Note: Regressions are based on year of birth averages and are weighted by the number of observations in each cell. 